\title{
IMPLEMENTING MARKET ACCESS
}

\author{
Kala Krishna \\ Suddhasatwa Roy \\ Marie Thursby
}

Working Paper 5593

\section{NATIONAL BUREAU OF ECONOMIC RESEARCH 1050 Massachusetts Avenue \\ Cambridge, MA 02138}

May 1996

We thank Theresa Greaney, Bill Novshek and seminar participants at the Midwest Trade Meetings, 1996, for helpful comments. Krishna is grateful for research support from the National Science Foundation under grant No. FBR9-9320825, and Roy and Thursby gratefully acknowledge support from the Purdue CIBER Technology Transfer Initiative. The usual disclaimer applies. This paper is part of NBER's research program in International Trade and Investment. Any opinions expressed are those of the authors and not those of the National Bureau of Economic Research.

(C) 1996 by Kala Krishna, Suddhasatwa Roy and Marie Thursby. All rights reserved. Short sections of text, not to exceed two paragraphs, may be quoted without explicit permission provided that full credit, including $\odot$ notice, is given to the source. 


\title{
IMPLEMENTING MARKET ACCESS
}

\begin{abstract}
The outcome of trade policies to increase access for foreign firms to the home country's market is shown to be sensitive to the implementation procedure used. The importance of the timing of moves between government and firms is highlighted by focusing on taxes and subsidies to implement minimum market share requirements. Both taxes and subsidies chosen by the home government after firms have picked prices create powerful incentives for firms to raise prices effects that are similar in nature to those found with quotas/VERs. We show that some degree of imprecision in implementing the target engenders less anticompetitive outcomes relative to perfect enforcement.
\end{abstract}

Kala Krishna

Department of Economics

The Pennsylvania State University

Kern Graduate Building

State College, PA 16802-3306

and NBER

Marie Thursby

Department of Economics

Purdue University

1310 Krannert Building

West Lafayette, IN 47907-1310

and NBER
Suddhasatwa Roy

Department of Economics

Purdue University

1310 Krannert Building

West Lafayette, IN 47907-1310 


\section{Introduction:}

While policies to increase market access have received much attention in recent years, scant attention has been paid to the issue of implementation of these policies. Consider, for example, the persistent calls to 'open up' the Japanese market by negotiating 'voluntary' minimum market share targets for U.S. firms in Japan. Though there is still considerable debate about the desirability of instituting such VIEs, the problem of implementation has never surfaced as being important. Irwin $(1994$, pg. 65) notes that $\ldots$...the United States never seems concerned about the mechanism by which "voluntary" bilateral agreements are carried out and acts as if the foreign government can solve the problem by fiat.'

Since it is well understood that enforcement is critical to the success of any results oriented policy, it is somewhat surprising that implementation per se, has been ignored. While Ethier and Horn (1993) and Cronshaw and Markusen (1995), among others, examine results oriented policies Greaney (1995) specifically incorporates the problem of implementation in her analysis. In her model, the government enforces the market share agreement by threatening the home firm with a financial penalty in the event the import target is not met. Nonetheless, neither this, nor other studies of VIEs, examine alternative methods of implementing market share requirements. ${ }^{1} \quad$ In reality, there are a number of ways of implementing a market share requirement, and the effects of the requirement depend critically on the details of the implementation procedure used.

1 See Dinopoulos and Kreinin (1990), Irwin (1993), Helpman and Krugman (1989), Kowalczyk (1994), Bjorksten (1994) and Nakamura (1995). 
Understanding these effects is important, since unlike VERs, no obvious procedure comes to mind for implementing a VIE. ${ }^{2}$ An implementation procedure that is feasible for one market may not be viable for another. For instance, setting minimum physical requirements on the use of imported intermediate goods, say semiconductors, may be a viable method of implementation when the number of purchasing firms is small. ${ }^{3}$ Such an implementation scheme would, however, be impossible to apply to the case of a final good demanded by many small agents, and, even when feasible, such a mechanism may have undesirable effects.

In this paper, we examine the use of tax/subsidy instruments to enforce market share requirements. While there are a number of instruments that could be used, taxes/subsidies are feasible in a wide range of environments where direct control is not. The tax/subsidy schemes that we consider reveal the importance of the sequence of moves between firms and the government, and they capture, albeit loosely, some aspects of MITI's handling of the semiconductor VIE. In particular, we consider taxes/subsidies that are set before firms make their strategic choices, as well as those which are imposed only if market outcomes violate the market share requirement. In the latter case, firms know that a violation of the market share target will, with some probability, trigger either a tax on the Japanese product or a subsidy on the U.S. good. The introduction of uncertainty attempts to capture MITI's imperfect monitoring of the VIE target in the semiconductor case and yields equilibrium outcomes where the U.S. firm's market share can (ex post) fall short of the mandated minimum (both of which are well documented in the semiconductor VIE). ${ }^{4}$ It also allows us to demonstrate that some degree of imprecision in implementing the target engenders less

2 The use of quotas is an obvious way to implement a VER since the exporting/importing country's government can physically monitor the exact amounts of the good leaving/entering the country, putting an end to the outflow/inflow the moment the quantitative ceiling is reached.

3 Tyson (1992, pg. 111-112) suggests that this was what was done in the first semiconductor agreement.

4 Both Irwin (1996) and Greaney (1995) discuss the continual seesawing of the U.S. market share below the 20 percent mark before finally climbing to just above the target in the fourth quarter of 1992. 
anticompetitive outcomes relative to perfect enforcement - perhaps, one reason behind the Japanese government's perpetual opposition to exact market shares in any VIE negotiation.

We show that a timing framework where governments choose tax/subsidy levels to implement market share requirements after firms have made their strategic decisions, but before markets clear, imparts incentive effects to tax/subsidy policy that are similar to those found with quotas/VERs. Such effects are absent from the existing literature on tax/subsidy policy, which with the exception of Carmichael (1987) and Gruenspecht (1988), has consistently adhered to a timing structure where governments are first movers. ${ }^{5}$ In keeping with that tradition, Greaney (1995) compares an import subsidy when the government moves first, with a VIE (enforced by a penalty threat) when the government moves second. She finds the two instruments have opposite effects on price, with the VIE raising prices. Our analysis suggests that this distinction is somewhat misleading since a VIE can be enforced by an import subsidy, and if the subsidy is triggered by a violation of the market share target, firms with market power will have an incentive to raise price.

In the case of a tax used to implement the VIE, our results are similar to Greaney's with the exception that in our model the VIE affects the strategic behavior not only of the Japanese firm but also that of the U.S. firm. Greaney assumes the Japanese government moves only after market shares have been observed - an assumption that leaves the U.S. firm's behavior unchanged and removes the kinds of strategic aspects of interest to us. On the other hand, her scheme has the decided advantage that the home government can implement the VIE with a minimum of information. In contrast, our ex post subsidy/tax imposes

5 Carmichael (1987) is the first to investigate an alternative timing framework where firms' pricing decisions precede government's choice of export subsidy levels. Citing evidence from practices followed by the U.S. Export-Import Bank to rationalize the sequence of government and firm actions, he shows that the rent seeking behavior of the firms yields positive export subsidies in equilibrium. This departure from the Eaton and Grossman (1986) result that first mover governments should tax the exports of Bertrand firms is again observed in Gruenspecht's (1988) model with big ticket differentiated products where governments set subsidy levels after firms choose prices. 
substantial informational requirements on the part of the government. ${ }^{6}$ Thus, since the government moves after firms set prices but before market shares are realized, successful implementation necessitates, for instance, perfect information regarding the demand functions. However, the assumption that governments face no informational constraints is not uncommon and characterizes most of the literature on strategic trade policy, e.g., Brander and Spencer (1985). ${ }^{7}$

It can be argued that our ex post subsidy accords better with MITI's actual handling of the semiconductor VIE than does the ex post tax on Japanese producers. As is well documented by Irwin (1996, pg. 53), MITI exercised its influence more on the demand side by trying to force Japanese firms (most of which were themselves semiconductor producers) to purchase more foreign chips. In fact, MITI's early efforts in 1987 to boost prices by directing domestic semiconductor producers to reduce output were shot down by the U.S. Semiconductor Industry Association.

The paper is organized as follows. In the next section, we look at the obvious ways of implementing VIEs, namely, via the use of taxes and subsidies when governments can precommit to their policies. Section 3 then identifies the kinds of incentive effects at work when governments are second movers. In order to clearly isolate the incentive effects of each instrument - tax and subsidy - on each of the firms, we first consider situations of one-sided market power and, later, combine the analyses to study the case of two-sided market power. When a subsidy on the U.S. product is used by the Japanese government to implement a minimum market share target, the U.S. monopoly firm has an incentive to raise price in order to trigger the subsidies. If monopoly power is on the Japanese side, the incentives are for the Japanese firm to raise price to reduce the amount of the subsidy granted or to 6 We are grateful to Theresa Greaney for pointing this out.

7 See, also, Brainard and Martimort (1992) for a discussion of the high informational requirements of strategic trade policy. 
eliminate it altogether. Under a tax policy, if market power is on the U.S. side the incentives are for the U.S. firm to raise its price to trigger taxes on the Japanese good. If power is on the Japanese side, then the incentive is to, always, prevent taxes from being invoked by charging higher prices. In Section 4, we put the two sides together and show that since price increases are still matched by each firm, both taxes and subsidies result in higher prices when firms have market power.

In Section 5, we present a simple but concrete numerical example to highlight the differences in equilibrium outcomes when comparing an ex ante policy with its ex post counterpart. By deriving prices, quantities, profits and welfare in each case, the exercise yields valuable insights into the economic effects of the various policies and helps rank them in terms of desirability from the Japanese and U.S. standpoints. For our example, instruments imposed ex post with some degree of imprecision engender less anticompetitive outcomes and higher profits for the Japanese firm than those which are perfectly enforced. To the extent that this result generalizes, it could explain the Japanese government's continued opposition to exact market shares in any VIE negotiation. Section 6 offers concluding comments.

\section{Implementation Through Taxes or Subsidies:}

While there may exist a number of different ways to implement market share requirements, we focus on the instrument of tax/subsidy as a natural policy to consider over a wide range of environments. Consider as an illustrative example the case where the U.S. negotiates a market access requirement with Japan. If a minimum market share for U.S. firms is the form of the market access requirement, a reasonable way to implement it may be to either tax Japanese firms until their sales fall enough for the market share of U.S. firms to attain the target specified, or to subsidize U.S. firms until their sales rise enough for the market share 
requirement to be met. While both methods appear reasonable ways of implementing this policy, in both the tax case and the subsidy case the timing of moves is critical to the nature of the outcomes that obtain. In particular, when there exists some degree of market power, allowing governments to set tax/subsidy levels after firms have made their strategic choices (but before markets clear) gives rise to incentive effects that are absent with the traditional timing scheme.

The literature has found some support for a second mover role of governments in real world settings. In fact, the timing scheme used in Carmichael (1987) is identical to our ex post scheme in that the governments set subsidy levels taking the firm prices as given, and the prices faced by consumers are the subsidy ridden 'effective' prices. Goldberg and Knetter (1995) provide evidence of a similar timing structure in the implementation of the Export Enhancement Program (EEP) for agricultural commodities, namely, wheat: U.S. exporters first submit bids specifying the price, quantity and quality of wheat (already negotiated with the foreign country) to be delivered; the Foreign Agricultural Service (FAS) then examines these bids and approves the subsidies if the quoted price is greater than the minimum acceptable price and the bonus is smaller than the maximum allowable bonus. In the interests of competition, both the minimum price and the maximum bonus are kept unknown to the firms, i.e., there is a positive probability that the EEP subsidy is not granted. While neither of these examples involves market share targets per se, this sequence of moves seems to be the most natural when examining VIEs. Further, our scheme has the added merit of capturing the real world concern that if firms anticipate their behavior will affect government policy, this anticipation must alter their strategic behavior. The next subsection discusses the issue of timing in greater detail and provides some justification for the specific timing structure used in this paper. 


\subsection{Ex Ante versus Ex Post Taxes and Subsidies:}

The behavior of firms when faced with these kinds of taxes and subsidies is very different depending on whether they think and act like these are given to them, or whether they think and act like these taxes/subsidies can be affected by their own behavior. In the former case, firms will not ask how changes in their behavior will change the taxes/subsidies offered by the government. In the latter case they will. The difference in the two cases can be thought of, at a formal level, as a difference in timing assumptions made. If the government chooses its tax/subsidy level first - what we call ex ante policy - then firms who subsequently decide on their behavior must take the government's choices as given. The government can look forward and take account of how its choices affect the choices made by firms. If on the other hand, firms decide what to do first, and then government chooses its tax/subsidy level what we call ex post policy - the government must take the firms' decisions as given while firms look forward and take account of how their behavior affects the government's behavior. Which timing assumption is appropriate depends on the ability of the government or the firm to precommit to its decision variable(s).

If taxes and subsidies are set ex ante, the analysis is trivial. Whatever be the market structure, the government looks forward and calculates the tax on Japanese firms or the subsidy on U.S. firms, or, even possibly, a combination of the two, which results in the market share requirement being met. If, for example, there is a single foreign and a single domestic firm competing in prices and producing differentiated goods that are substitutes for one another, and if demand is linear, then the best response functions of the U.S. firm $B_{2}\left(p_{1}\right)$, and the Japanese firm $B_{1}\left(p_{2}\right)$, can be depicted as in Figure $1 .{ }^{8}$ The equilibrium firm (and consumer) prices are given by the intersection of the best response functions, and

8 As usual, the best response function for firm 1 (firm 2) is its profit maximizing price given the price chosen by firm 2 (firm 1). 
their relative slopes are as shown to ensure stability of equilibrium. The combination of consumer prices which result in a market share for the U.S. firm at the free trade level can be depicted by an upward sloping line $E E$, going through the equilibrium price pair and lying between the two best response functions. ${ }^{9}$

If a larger market share for the U.S. is required by the market share rule, it can be depicted by a line to the right of $E E$ such as $M M$. Now this higher market share can be attained by setting a tax on the Japanese firm. As the tax results in the Japanese firm setting a higher price for any given U.S. price, this tax must move the Japanese firm's best response function to the right to go through the point $C$.

Alternatively, this higher U.S. market share can be attained by giving a subsidy per unit to the U.S. firm which moves its best response function down and to the right through the point $A .^{10}$ Notice that the two implementation procedures result in very different consumer prices. Consumer prices are raised by the scheme when implemented by a tax and reduced by it when implemented by a subsidy. Note, also, that the appropriate mix of tax and subsidy policies can, by shifting both firms' best response functions accordingly, realize any point on $M M$ lying between $A$ and $C$.

Now consider ex post taxes and subsidies. In a situation where the government wants to implement market access but cannot precommit to a tax/subsidy level there is considerable room for strategic behavior on the part of the firms. For instance, a government may announce that while it is serious about ensuring that the market share requirement is met, it will not intervene actively unless free market forces continue to violate the market share 9 In the case of linear demand, the locus of consumer price combinations $\left(p_{1}^{C}, p_{2}^{C}\right)$ satisfying a market share constraint of $k(0<k<1)$ with equality is represented by the equation $p_{2}^{C}=\eta_{0}+\eta_{1} p_{1}^{C}$ where $\eta_{0}=\frac{(1-k) a_{2}-k a_{1}}{(1-k) b+k c}, \eta_{1}=\frac{(1-k) c+k b}{(1-k) b+k c}$, and the demand for $\operatorname{good} i$ is $q_{i}\left(p_{i}^{C}, p_{j}^{C}\right)=a_{i}-b p_{i}^{C}+c p_{j}^{C} ; b>c>0, a_{i}>$ $0 ; i=1,2 ; j \neq i$. It is easy to verify that this is the equation of a straight line steeper than 2's best response but flatter than 1 's best response.

10This is the type of subsidy that Greaney (1995) considers when comparing a "VIE" with an import subsidy. 
targets. In such settings, firms can exploit the fact that their actions influence the government's choice of policies. Much of the concern in the real world about the effect of market share requirements has to do with how their presence will influence the behavior of firms. Such issues involve considerations of strategic interaction and cannot be analyzed within the ex ante policy framework. These questions can, however, be addressed meaningfully within the context of ex post tax/subsidy policy. Consequently, an understanding of the effects of such policies is important and relevant.

\section{Ex Post Policies with One-Sided Market Power:}

The easiest way to develop some intuition about how ex post policy, geared towards implementing market share targets, affects firms' incentives is to consider situations of one-sided market power, i.e., either the Japanese or the U.S. firm has market power but not both. Let us assume that demand is linear, products are differentiated, firms are risk neutral and that the perfectly competitive firms make identical products. There are, then, four simple combinations of policy regime and market structure to consider:

(a) Subsidy policy with a U.S. monopoly firm and a competitive Japanese industry,

(b) Subsidy policy with a Japanese monopoly firm and a competitive U.S. industry,

(c) Tax policy with a U.S. monopoly firm and a competitive Japanese industry,

(d) Tax policy with a Japanese monopoly firm and a competitive U.S. industry.

The above serve the purpose of showing that even within such simple structures, ex post tax/subsidy policies create important incentive effects that are absent in their ex ante counterparts. 


\subsection{Subsidy policy with a U.S. monopoly firm and a competitive Japanese industry:}

First consider the incentive effects under $(a)$. Recall that the goods made in the two countries are imperfect substitutes for each other and that the Japanese industry is behaving competitively and pricing at marginal cost. The U.S. firm has monopoly power and has a first mover advantage over the Japanese government. It understands that if it charges a price such that demand for its product at this price violates the market share constraint, it will be given the subsidy per unit needed to meet the pre-specified market share. In this situation, the U.S. firm has an incentive to raise price as high as possible, to infinity, as there are no limits on its ability to exploit the government. To make the problem bounded, assume the Japanese government announces that whenever the market share constraint is violated the U.S. firm will be subsidized stochastically such that for any Japanese price, a higher divergence from the market share satisfying U.S. price will be associated with a lower probability of the subsidy being granted. ${ }^{11}$ We introduce uncertainty to capture the notion that a government's enforcement of a VIE target may be less than perfect. Uncertainty also helps to mitigate the U.S. firm's rent seeking incentives because, intuitively, some degree of imprecision should reduce either firm's power to strategically exploit the VIE target. This is trivially true for the U.S. firm in the case of a subsidy because under certainty it has an incentive to charge an infinitely high price. ${ }^{12}$

Before proceeding to the formal analysis, some explanations regarding notation are in

11This can limit the U.S. firm's rent-seeking ability since the incentive to charge an arbitrarily high price is dampened by the small probability of getting the subsidy.

${ }^{12}$ Further, even if an upper bound is placed on the U.S. firm's price, complete certainty regarding that bound leads to excess strategic maneuvering by the Japanese firm. For instance, if we use the Carmichael (1987) type of constraint where the subsidy is revoked with certainty whenever the U.S. firm prices above its ordinary best response, the Japanese firm chooses its ordinary best response for U.S. prices above the free trade level, but has an incentive to cut prices discontinuously for lower U.S. prices and charge a price infinitesimally smaller than the one that just triggers the subsidy. 
order. In this case, the competitive Japanese firm price $p_{1}$, is always equivalent to the consumer price $p_{1}^{C} .{ }^{13} \quad$ However, the U.S. consumer price $p_{2}^{C}$ equals the firm price $p_{2}$ only when the subsidy is not realized. Otherwise, when the subsidy is triggered, $p_{2}^{C}$ equals $g_{2}\left(p_{1}\right)$ where $g_{2}\left(p_{1}\right)$ is the U.S. consumer price that makes the market share constraint just bind for given Japanese firm price $p_{1}$. Hence, given firm prices $\left(p_{1}, p_{2}\right)$, demand for the U.S. good is $q_{2}\left(p_{1}, g_{2}\left(p_{1}\right)\right)$ if the subsidy is invoked and demand equals $q_{2}\left(p_{1}, p_{2}\right)$ if the subsidy is not granted. The locus of prices $\left(p_{1}, g_{2}\left(p_{1}\right)\right)$ traces out an upward sloping line $M M$ (shown in Figure 3) such that the market access constraint is binding only for firm prices lying above (and to the left) of this line.

Now, let $f\left(p_{1}, p_{2}\right)$ be the probability of the subsidy being granted for any given price combination above $M M$. Assume that $f($.$) is nondecreasing in p_{1}$ and nonincreasing in $p_{2} .{ }^{14}$ Then, given constant unit cost $r_{2}$, for price combinations $\left(p_{1}, p_{2}\right)$ above $M M$, we can define the U.S. firm's expected profits as

$$
\begin{aligned}
\bar{\pi}_{2}\left(p_{1}, p_{2}\right) & =f(.)\left(p_{2}-r_{2}\right) q_{2}\left(p_{1}, g_{2}\left(p_{1}\right)\right)+[1-f(.)]\left(p_{2}-r_{2}\right) q_{2}\left(p_{1}, p_{2}\right) \\
& =f(.) \pi_{2}^{H}\left(p_{1}, p_{2}\right)+[1-f(.)] \pi_{2}\left(p_{1}, p_{2}\right)
\end{aligned}
$$

where $\pi_{2}^{H}\left(p_{1}, p_{2}\right)$ is its profit at subsidized prices while $\pi_{2}\left(p_{1}, p_{2}\right)$ is its ordinary profit function. $\pi_{2}^{H}\left(p_{1}, p_{2}\right)$ and $\pi_{2}\left(p_{1}, p_{2}\right)$ are depicted in Figure 2. Notice that for any given $p_{1}$, $\pi_{2}^{H}\left(p_{1}, p_{2}\right)$ is represented by a straight line with a constant positive slope of $q_{2}\left(p_{1}, g_{2}\left(p_{1}\right)\right){ }^{15}$ Figure 2 also shows $\bar{\pi}_{2}\left(p_{1}, p_{2}\right)$ for the special case of constant probability of subsidy.

Let $B_{2}\left(p_{1}\right)$ denote the U.S. firm's ordinary best response in the absence of a market

13Henceforth, $p_{i}$ will always denote the price charged by firm $i$ while the consumer price will be represented by $p_{i}^{C}$. Recall that firms in the competitive industry (Japanese firms, in this case) are identical in every respect and, hence, when good $i$ is competitively produced, $p_{i}$ refers to the price, of the representative firm. 14For instance, we could use $f\left(p_{1}, p_{2}\right)=1-h\left(p_{2}-g_{2}\left(p_{1}\right)\right)$ where $h \in(0,1)$, and $h^{\prime}() \geq$.0 since we know that $g_{2}^{\prime}()>$.0 . Henceforth, for simplicity, we shall assume $f\left(p_{1}, p_{2}\right)$ to be a constant.

15 Given any $p_{1}, q_{2}\left(p_{1}, g_{2}\left(p_{1}\right)\right)$ is simply the demand for firm 2's product at the corresponding point on the market share line $M M . q_{2}\left(p_{1}, g_{2}\left(p_{1}\right)\right)$ decreases continuously as $p_{1}$ increases and we move up along $M M$ 
share constraint. Define $\bar{B}_{2}\left(p_{1}\right)$ as the interior maximizer of $\bar{\pi}_{2}\left(p_{1}, p_{2}\right)$ which we assume bounded and concave. If the market share constraint is binding, the relevant profit function is $\bar{\pi}_{2}\left(p_{1}, p_{2}\right)$. On the other hand, if the constraint is not binding, then the U.S. firm maximizes $\pi_{2}\left(p_{1}, p_{2}\right)$ as before. As $\bar{\pi}_{2}\left(p_{1}, p_{2}\right)=\pi_{2}\left(p_{1}, p_{2}\right)$ at $p_{2}=g_{2}\left(p_{1}\right)$, the overall profit function is given by

$$
\begin{aligned}
\widehat{\pi}_{2}\left(p_{1}, p_{2}\right) & =\pi_{2}\left(p_{1}, p_{2}\right) \text { for } p_{2} \leq g_{2}\left(p_{1}\right) \\
& =\bar{\pi}_{2}\left(p_{1}, p_{2}\right) \text { for } p_{2}>g_{2}\left(p_{1}\right)
\end{aligned}
$$

In Figure 2 , the bold line traces out $\widehat{\pi}_{2}\left(p_{1}, p_{2}\right)$. Note that for prices to the right of the $p_{2}$ at which $\pi_{2}\left(p_{1}, p_{2}\right)$ and $\pi_{2}^{H}\left(p_{1}, p_{2}\right)$ intersect, the market share constraint is violated and $\bar{\pi}_{2}\left(p_{1}, p_{2}\right)$ is the relevant profit for these prices. Let the maximizer of $\widehat{\pi}_{2}\left(p_{1}, p_{2}\right)$ be denoted by $\widehat{B}_{2}\left(p_{1}\right)$. Then, there are three possibilities to consider when deriving the U.S. firm's overall best response. Given Japanese price $p_{1}, \pi_{2}($.$) and \pi_{2}($.$) may intersect at a p_{2}$ where (i) both are increasing in $p_{2}$, (ii) both are decreasing in $p_{2}$, or (iii) $\pi_{2}($.$) is decreasing and \bar{\pi}_{2}($.$) is$ increasing in $p_{2}$. Recall that at $p_{2}=g_{2}\left(p_{1}\right), \bar{\pi}_{2}()=.\pi_{2}($.$) and \bar{\pi}_{2}($.$) has a larger slope than$ $\pi_{2}($.$) . Then, given the definition of \hat{\pi}_{2}\left(p_{1}, p_{2}\right)$, we must have $\widehat{B}_{2}\left(p_{1}\right)=\bar{B}_{2}\left(p_{1}\right)$ in case (i) and $\widehat{B}_{2}\left(p_{1}\right)=B_{2}\left(p_{1}\right)$ in case (ii). In case (iii), $\widehat{B}_{2}\left(p_{1}\right)$ equals either $\bar{B}_{2}\left(p_{1}\right)$ or $B_{2}\left(p_{1}\right)$ depending on whether the peak of $\bar{\pi}_{2}($.$) is higher or lower than that of \pi_{2}($.$) . Case (i) occurs when$ $B_{2}\left(p_{1}\right)>g_{2}\left(p_{1}\right)$, case (ii) corresponds to situations where $\bar{B}_{2}\left(p_{1}\right)<g_{2}\left(p_{1}\right)$ while case (iii) occurs when $B_{2}\left(p_{1}\right)<g_{2}\left(p_{1}\right)<\bar{B}_{2}\left(p_{1}\right)$. Note that Figure 2 is representative of case (i).

Figure 3 shows $\bar{B}_{2}\left(p_{1}\right), B_{2}\left(p_{1}\right)$ and the market share line $M M$ in price space. Note that for $p_{1}$ less than $R_{1}^{\prime}$ (the $p_{1}$ at which $M M$ intersects $B_{2}\left(p_{1}\right)$ ) we are in case (i), while case (ii) corresponds to $p_{1}$ greater than $R_{1}^{\prime \prime \prime}$ (the $p_{1}$ at which $M M$ intersects $\bar{B}_{2}\left(p_{1}\right)$ ). Case (iii) occurs for Japanese prices in the intermediate range between $R_{1}^{\prime}$ and $R_{1}^{\prime \prime \prime}$. Hence, from the above analysis, we may depict the overall U.S. best response $\hat{B}_{2}\left(p_{1}\right)$ by the bold line in Figure 3 
which assumes one switchover point $R_{1}^{\prime \prime}$ at which $\widehat{B}_{2}\left(p_{1}\right)$ jumps down from $\bar{B}_{2}\left(p_{1}\right)$ to $B_{2}\left(p_{1}\right)$.

Now, let $R_{1}$ be any Japanese competitive price resulting in a free trade equilibrium point $A$, unconstrained by any market share target. If the market access requirement specifies a U.S. share greater than that in free trade, $M M$ must lie below $B_{2}\left(p_{1}\right)$ at $p_{1}=R_{1}$, and so, $R_{1}$ must lie to the left of $R_{1}^{\prime}$ in Figure 3. Clearly, this corresponds to case (i) and the U.S. firm maximizes its profit by picking a price $\bar{B}_{2}\left(R_{1}\right)$, resulting in the equilibrium at point $C$. In equilibrium, there is a positive probability of a subsidy being granted and the U.S. firm charges a higher price compared to free trade.

\subsection{Subsidy policy with a Japanese monopoly firm and a compet- itive U.S. industry:}

Now, consider the incentive effects under $(b)$ where the Japanese firm has the market power. Analogous to the previous case, given firm prices $\left(p_{1}, p_{2}\right)$, demand for the Japanese good is $q_{1}\left(p_{1}, g_{2}\left(p_{1}\right)\right)$ if the subsidy is invoked and demand equals $q_{1}\left(p_{1}, p_{2}\right)$ if the subsidy is not granted. The Japanese firm knows that if the market share requirement is not met, a subsidy will be given (stochastically) to the U.S. firms. In this event, demand for the Japanese firm will fall, along with its profit. If, however, the Japanese firm were to raise its price, it could reduce or eliminate the subsidy given to the U.S. firms, and at least get a higher price in return for a lower demand. This is what creates incentives for price increases by the Japanese firm even when the U.S. firms are pricing competitively.

Proceeding similarly to the previous case, for any U.S. firm price $p_{2}$, let $g_{1}\left(p_{2}\right)$ be the Japanese consumer price that satisfies the market share constraint with equality. Then, given $p_{2}$, unit cost $r_{1}$ and the probability of subsidy $f($.$) , the Japanese firm's expected profit$ function for prices to the left of $M M$ is:

$$
\bar{\pi}_{1}\left(p_{1}, p_{2}\right)=f(.)\left(p_{1}-r_{1}\right) q_{1}\left(p_{1}, g_{2}\left(p_{1}\right)\right)+[1-f(.)]\left(p_{1}-r_{1}\right) q_{1}\left(p_{1}, p_{2}\right)
$$




$$
=f(.) \pi_{1}^{L}\left(p_{1}\right)+[1-f(.)] \pi_{1}\left(p_{1}, p_{2}\right)
$$

$\pi_{1}\left(p_{1}, p_{2}\right)$ is the Japanese firm's ordinary profit function while $\pi_{1}^{L}\left(p_{1}\right)$ is its profit at the subsidized prices $\left(p_{1}, g_{2}\left(p_{1}\right)\right)$, and equals its ordinary profit at the corresponding point on the $M M$ line. For given $p_{2}$, note that the first derivative of $\pi_{1}^{L}\left(p_{1}\right)$ is greater than that of $\pi_{1}\left(p_{1}, p_{2}\right)$ at $p_{1}=g_{1}\left(p_{2}\right)$, i.e., on the $M M$ line, since demand at the subsidized prices is more inelastic than ordinary demand. Since $\bar{\pi}_{1}\left(p_{1}, p_{2}\right)$ is a convex combination of $\pi_{1}^{L}\left(p_{1}\right)$ and $\pi_{1}\left(p_{1}, p_{2}\right)$ and $f($.$) is constant, the derivative of \pi_{1}\left(p_{1}, p_{2}\right)$ must also be greater than that of $\pi_{1}\left(p_{1}, p_{2}\right){ }^{16}$ Figure 4 depicts $\pi_{1}^{L}\left(p_{1}\right)$, assumed concave, $\pi_{1}\left(p_{1}, p_{2}\right)$ and $\pi_{1}\left(p_{1}, p_{2}\right)$.

The Japanese firm's overall profit function is given by

$$
\begin{aligned}
\hat{\pi}_{1}\left(p_{1}, p_{2}\right) & =\pi_{1}\left(p_{1}, p_{2}\right) \text { for } p_{1} \geq g_{1}\left(p_{2}\right) \\
& =\bar{\pi}_{1}\left(p_{1}, p_{2}\right) \text { for } p_{1}<g_{1}\left(p_{2}\right)
\end{aligned}
$$

$\widehat{\pi}_{1}\left(p_{1}, p_{2}\right)$ is shown as the bold curve in Figure 4. Note that, now, for prices less than the $p_{1}$ at which $\pi_{1}^{L}\left(p_{1}\right)$ and $\pi_{1}\left(p_{1}, p_{2}\right)$ intersect, the market share constraint is violated and $\bar{\pi}_{1}\left(p_{1}, p_{2}\right)$ is the relevant profit. Let $\widehat{B}_{1}\left(p_{2}\right)$ be the maximizer of $\widehat{\pi}_{1}\left(p_{1}, p_{2}\right)$. Again, we have three cases to consider in deriving the Japanese firm's overall best response. Given U.S. price $p_{2}, \pi_{1}($.$) and \bar{\pi}_{1}($.$) may intersect at a p_{1}$ where (i) both are increasing in $p_{1}$, (ii) both are decreasing in $p_{1}$, or (iii) $\pi_{1}($.$) is decreasing and \bar{\pi}_{1}($.$) is increasing in p_{1}$. Then, from the definition of $\widehat{\pi}_{1}\left(p_{1}, p_{2}\right)$, we must have $\widehat{B}_{1}\left(p_{2}\right)=B_{1}\left(p_{2}\right)$ in case $(\mathrm{i})$ and $\widehat{B}_{1}\left(p_{2}\right)=\bar{B}_{1}\left(p_{2}\right)$ in case (ii). In case (iii), $\widehat{B}_{1}\left(p_{2}\right)$ equals $g_{1}\left(p_{2}\right)$, i.e., the Japanese firm prices along $M M$. Case (i) occurs when $B_{1}\left(p_{2}\right)>g_{1}\left(p_{2}\right)$, case (ii) corresponds to situations where $\bar{B}_{1}\left(p_{2}\right)<g_{1}\left(p_{2}\right)$ while case (iii) occurs when $B_{1}\left(p_{2}\right)<g_{1}\left(p_{2}\right)<\bar{B}_{1}\left(p_{2}\right)$. Figure 4 corresponds to the situation in case (ii).

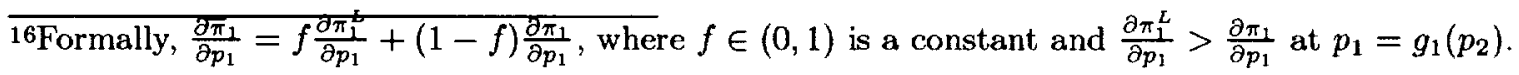


Now, consider Figure 5 which shows $B_{1}\left(p_{2}\right), \bar{B}_{1}\left(p_{2}\right)$ and the market share line $M M$ in price space. As drawn, the Japanese firm's profit, as we move up along $M M$, increases up to the point $D$ (where an iso-profit curve is tangent to $M M$ ) and then decreases. For U.S. prices less than $R_{2}^{\prime}$ (the $p_{2}$ at which $M M$ intersects $B_{1}\left(p_{2}\right)$ ) we are in case (i) and the best response is to choose $B_{1}\left(p_{2}\right)$. For $p_{2}$ greater than $R_{2}^{\prime \prime}$ (the $p_{2}$ on $M M$ corresponding to the price $R_{1}^{\prime}$ which maximizes $\pi_{1}^{L}\left(p_{1}\right)$ ), we are in case (ii) and the Japanese firm is best off pricing along $\bar{B}_{1}\left(p_{2}\right)$. Note that for $p_{2} \geq R_{2}^{\prime \prime \prime}$ (the $p_{2}$ at which $B_{1}\left(p_{2}\right)$ intersects $\left.R_{1}^{\prime}\right), \bar{B}_{1}\left(p_{2}\right)$ must lie to the left of $B_{1}\left(p_{2}\right)$. Finally, for prices in the intermediate range between $R_{2}^{\prime}$ and $R_{2}^{\prime \prime}$, $\pi_{1}\left(p_{1}, p_{2}\right)$ is decreasing in $p_{1}$ while $\pi_{1}^{L}\left(p_{1}\right)$ is increasing in $p_{1}$ at $g_{1}\left(p_{2}\right)$. Hence, $\bar{\pi}_{1}($.$) may be$ increasing - case (iii) with $\widehat{B}_{1}\left(p_{2}\right)=g_{1}\left(p_{2}\right)$ - or decreasing - case (ii) with $\widehat{B}_{1}\left(p_{2}\right)=\bar{B}_{1}\left(p_{2}\right)$. Since $\bar{\pi}_{1}($.$) is a convex combination of \pi_{1}\left(p_{1}, p_{2}\right)$ and $\pi_{1}^{L}\left(p_{1}\right)$, it is likely to be increasing for prices close to $R_{2}^{\prime}$ but is likely to be decreasing for prices close to $R_{2}^{\prime \prime}$. This, in turn, suggests that $\widehat{B}_{1}\left(p_{2}\right)$ lies along the $M M$ line for prices close to $R_{2}^{\prime}$ and lies on $\bar{B}_{1}\left(p_{2}\right)$ for prices close to $R_{2}^{\prime \prime}$. The overall Japanese best response depicted by the bold line in Figure 5 is drawn under the assumption that $\bar{B}_{1}\left(p_{2}\right)$ intersects $M M$ at prices $\left(\widetilde{R}_{1}, \widetilde{R}_{2}\right)$.

In Figure 5, suppose the U.S. good is priced competitively at $R_{2}$ and the market share target is greater than the free trade level. Then at $R_{2}, M M$ must lie to the right of $B_{1}\left(p_{2}\right)$ and must intersect $B_{1}\left(p_{2}\right)$ at some point $E$ as depicted. We are then in case (ii) and the Japanese firm prices along $\bar{B}_{1}\left(p_{2}\right)$ resulting in an equilibrium at point $C$. Compared to the free trade equilibrium at $A$, the ex post subsidy policy yields a higher Japanese price and a (stochastically) lower consumer price for the U.S. good. ${ }^{17}$

$\overline{17 \text { If the competitive U.S. price lies between }} R_{2}^{\prime}$ and $\widetilde{R}_{2}$, the ex post subsidy policy results in an unchanged U.S. price, a higher Japanese price and a zero subsidy in equilibrium. 


\subsection{Tax policy with a U.S. monopoly firm and a competitive Japanese industry:}

Turning to tax policy, consider $(c)$. The ordinary best response function $B_{2}\left(p_{1}\right)$, and the market share constraint $M M$, are as depicted in Figure 6. Note that, analogous to the previous subsidy policy cases, $M M$ must again lie to the right of the point where the competitive Japanese price $R_{1}$ intersects $B_{2}\left(p_{1}\right)$ since we are considering a market share requirement set above the free trade level. However, in contrast to the subsidy case, the analysis is carried out with a deterministic tax, i.e., perfect enforcement of the VIE is assumed. The motivation is to emphasize that it is the timing of moves, and not the uncertainty, which determines the nature of the realized outcomes. In particular, an $e x$ post tax/subsidy instrument is always more anticompetitive in its effects than its ex ante counterpart. ${ }^{18}$

When the Japanese competitive price is $R_{1}$, the U.S. firm has an incentive to raise its price in response to the tax policy. By raising its price, it can ensure that its market share falls below the required level, triggering a tax on the Japanese industry which pulls up the real price to consumers of the Japanese good in tandem with the U.S. price along $M M$. The profit maximizing point along $M M$ for the U.S. firm is the tangency point at $D$. Hence, when the Japanese price is $R_{1}$, the U.S. firm is best off choosing to invoke taxes on the Japanese firms, which restricts their ability to compete in their own market, and allows the U.S. firm to further enhance its monopoly power. It charges a price $p_{2}^{H}$ that is greater than the free trade price and that results in an equilibrium at point $C$. Notice that the incentive effects of the tax results in behavior on the U.S. firm's part that is similar in nature to its pricing strategy under a VER on the rival good. (See Krishna, 1989).

${ }^{18}$ The analysis with a stochastic tax is analogous to that in the subsidy case and results in best responses that are similar in nature. In fact, the equilibrium outcomes with a stochastic tax are explicitly calculated for the example in section 5 , allowing for comparison with the deterministic tax. 
Alternatively, it can choose not to invoke taxes on the Japanese industry and get the highest profit it can for this option. It compares its maximum profit from not invoking taxes with the maximum profit it can get by triggering taxes. It will choose not to invoke taxes on the rival industry if the Japanese price is high enough, and will trigger taxes otherwise. This is illustrated in Figure 6, where the U.S. firm's best response is depicted by the bold line. Note that it is discontinuous at $p_{1}=\hat{p}_{1}$ where the profits from its two options are equal. ${ }^{19}$

\subsection{Tax policy with a Japanese monopoly firm and a competitive U.S. industry:}

Finally, consider $(d)$ where the Japanese firm has the market power and is taxed whenever the market share target is violated. Now, for any U.S. price $p_{2}$, the Japanese firm will never want to charge a price to the left of $M M$ since the resulting tax raises its consumer price to the corresponding point on $M M$. Consequently, it is better off raising its price to lie on $M M$ and at least getting the benefit of a higher price. Thus, its best response to any U.S. price can never lie to the left of $M M$. This best response is depicted by the bold line in Figure 7. Again, if $M M$ represents a U.S. market share greater than the free trade level, $M M$ lies to the right of $A$ and the tax policy raises the Japanese price from that at $A$ to that at $C$. Note that the Japanese firm's best response is reminiscent of the case of a VER on its product.

\section{Ex Post Policy with Two-Sided Market Power:}

The effect of two-sided market power can be thought of as combining the elements of the analysis so far. If, for example, we consider the implementation of a minimum market share using a subsidy on the U.S. firm, then two-sided market power can be thought of as 19It can be verified that when $p_{1}=\hat{p}_{1}$, the U.S. firm's best strategy is to randomize between $p_{2}^{H}$ and $p_{2}^{L}$ (see Krishna, 1989, for a similar proof). 
superimposing the best response of a U.S. firm having market power, case (a) and Figure 3 above, on the best response function of a Japanese firm having market power, case $(b)$ and Figure 5 above. This is done in Figure 8 where the best responses for the Japanese and U.S. firms are labelled $\hat{B}_{1}\left(p_{2}\right)$ and $\hat{B}_{2}\left(p_{1}\right)$ respectively. When the U.S. firm alone exercises market power it has an incentive to raise prices in the hope of triggering subsidies. On the other hand, when the power is on the Japanese side, there is an incentive to increase prices to reduce the amount of the subsidy, as well as to receive a higher price for its product should the demand lowering subsidy occur. Since price increases are still matched by each firm (strategic complements), putting both the sides together results in higher prices compared to the free trade equilibrium.

If we consider the implementation of a minimum market share using taxes on the Japanese firm, then we need to superimpose the best response of a U.S. firm having market power, case $(c)$ and Figure 6 above, on the best response function of a Japanese firm having market power, case $(d)$ and Figure 7 above. Doing so gives Figure $9 .{ }^{20}$

Observe that the two best response functions do not intersect. There is no pure strategy equilibrium and the mixed strategy equilibrium consists of the U.S. firm mixing between the two points $p_{2}^{L}$ and $p_{2}^{H}$ in Figure 6 , and the Japanese firm charging $\hat{p}_{1}$. The form of the equilibrium is analogous to that in Krishna (1989). The U.S. firm can either set a high price and trigger a tax on the Japanese firm which raises its price, or choose to ignore that option, and price along its old best response. It will ignore the option when the Japanese price is high enough and use it otherwise. When the Japanese firm charges $\hat{p}_{1}$, the U.S. firm is indifferent between its two options and is willing to mix between them in any way needed. The mixing is designed to make the Japanese firm choose to charge $\hat{p}_{1}$. In equilibrium, for 20Alternatively, if we were to consider a stochastic tax, the situation would be similar in nature to the subsidy case. In fact, the example in the next section depicts the outcomes with either type of tax, demonstrating that a non-deterministic instrument is less collusive than a deterministic one. 
market shares close to free trade levels, the prices charged are higher. The profits of the U.S. firm are higher in equilibrium.

Hence, both the obvious schemes - taxes and subsidies - to use in implementing market share requirements are seen to carry adverse incentive baggage with them in that, either scheme tends to raise prices charged by firms.

\section{An Example:}

This section presents a simple but concrete numerical example to highlight the importance of the timing of moves between government and firms in the presence of a minimum market share target. By focusing on the differences in equilibrium outcomes when comparing $e x$ ante policies with their ex post counterparts, the exercise yields valuable insights into the economic effects of the various policies and helps rank them in terms of desirability from the Japanese government's standpoint. Further, by examining an alternative tax instrument, viz. the ex post stochastic tax, we demonstrate that some degree of imprecision in enforcing the VIE target makes for less anticompetitive outcomes. ${ }^{21}$

Using linear demand and a constant probability of subsidy/tax of 0.2 in a duopolistic setting, we consider a case where the U.S. firm initially has $46 \%$ of the Japanese market prior to the U.S. government's successful negotiation of a $60 \%$ VIE target. ${ }^{22}$ Table 1 reports the resulting firm prices, consumer prices, outputs, profits, subsidy expenditures, tax revenues, Japanese consumer surplus and Japanese welfare across six different policy

21While the formal analysis has considered only ex post deterministic taxes, an ex post stochastic tax can readily be shown to yield best responses similar in nature to those found in the ex post subsidy setting. 22The example uses the demand structure $q_{i}=a_{i}-b p_{i}+c p_{j}, i, j=1,2 ; j \neq i$; with $a_{1}=5, a_{2}=4, b=2, c=1$; and costs of production $r_{1}=r_{2}=1$. These demands are derived from the underlying utility function $U\left(q_{1}, q_{2}\right)=\alpha_{1} q_{1}+\alpha_{2} q_{2}-\left(\beta q_{1}^{2}+2 \gamma q_{1} q_{2}+\beta q_{2}^{2}\right) / 2$ with $a_{i}=\left(\alpha_{i} \beta-\alpha_{j} \gamma\right) /\left(\beta^{2}-\gamma^{2}\right), b=\beta /\left(\beta^{2}-\gamma^{2}\right)$ and $c=\gamma /\left(\beta^{2}-\gamma^{2}\right)$. Consumer surplus with prices $\left(p_{1}, p_{2}\right)$ and quantities $\left(q_{1}, q_{2}\right)$ is given by $U\left(q_{1}, q_{2}\right)-\left(\pi_{1}+\pi_{2}\right)$. See Singh and Vives (1984) for details. Similar qualitative results hold for different parameter values, and also for the case where the probability of subsidy/tax is allowed to vary with firm prices. 
regimes: no VIE target, ex ante subsidy, ex ante tax, ex post subsidy, ex post certain tax and ex post stochastic tax. ${ }^{23}$ Note that U.S. welfare is simply the U.S. firm's profit. Also note that, in this example, though the equilibria (in firm prices) are in pure strategies, one should be very careful when comparing the ex post policies with their ex ante counterparts since in the ex post case, the consumer prices (and, hence, quantities, profits and welfare) reported in the table are only expected values.

At the very outset, we notice that an ex post subsidy results in higher consumer prices than an ex ante subsidy: $(2.37,2.16)$ compared to $(2.10,1.40)$. In fact, unlike the ex ante subsidy, the ex post subsidy actually increases consumer prices above free trade levels! The Japanese consumers are better off under the ex ante subsidy with a consumer surplus of 7.66 (compared to 5.05 under the ex post subsidy). However, from the Japanese government's viewpoint, the ex post subsidy dominates the ex ante subsidy in terms of profit: (3.32 compared to 2.42), and subsidy expenditure: the ex ante subsidy costs a whopping 4.13 while the ex post subsidy only costs .34 ! In fact, the unweighted sum of consumer surplus and profit less subsidy expenditures assigns a higher value to the ex post subsidy: welfare is 8.03 under the ex post subsidy but is only 5.96 with the ex ante subsidy. Nevertheless, the Japanese government may prefer the ex ante subsidy if consumer surplus is weighted more heavily in national welfare. The U.S. firm is better off with the ex ante subsidy than with the ex post subsidy. ${ }^{24}$

The tendency for prices to rise more when firms move first is again found in the tax case. The ex post certain tax yields consumer prices of $(3.14,2.54)$ and consumer surplus of only 2.83 while the ex ante tax results in lower prices of $(2.80,2.20)$ and a higher consumer 23Japanese welfare is measured as the unweighted sum of consumer surplus, firm profit and tax revenues in the case of a tax instrument, and as the unweighted sum of consumer surplus and firm profit less subsidy expenditures in the case of a subsidy instrument.

24Note that consumer prices and outputs with a VIE and an import subsidy in Greaney's model correspond to those with an ex ante tax and an ex ante subsidy, respectively, in our framework. 
surplus of 4.05. Since Japanese profit plus tax revenue is larger with the ex ante tax, the ex ante tax clearly dominates the ex post certain tax in terms of welfare. This serves to stress the point that the price increases are caused by the timing of moves and not by the uncertainty.

In fact, some degree of imprecision in the VIE's specification reduces the extent to which the firms can strategically exploit the VIE and yields less anticompetitive outcomes relative to the ex post certain tax. This is borne out in Table 1, where firm and consumer prices are lower for both goods with the ex post stochastic tax compared to the ex post certain tax. This translates into a much higher Japanese consumer surplus of 4.79 with the ex post stochastic tax relative to the low figure of 2.83 with the ex post certain tax. Further, since Japanese profit plus tax revenue is also higher, Japanese welfare is much higher with the $e x$ post stochastic tax : 8.02 compared to 5.51 . The intuition is that the average U.S. market share with the stochastic tax is .49 (not shown in Table 1) and, so, the uncertain ex post tax is less restrictive than the certain ex post tax. ${ }^{25}$ However, not surprisingly, the U.S. is better off with the ex post certain tax enjoying a welfare of 3.13 compared to 2.49 .

More interestingly, the ex post stochastic tax yields a higher consumer surplus than the ex ante tax: 4.79 compared to 4.05 : due to smaller consumer prices: $(2.47,2.17)$ compared to $(2.80,2.20)$. Further, the higher profit plus tax revenue for the Japanese firm implies a larger national welfare with the stochastic tax and, consequently, the Japanese government would pick the ex post stochastic tax if faced with a choice between a stochastic tax and an ex ante tax. As for U.S. welfare, it continues to be better off with the ex post certain tax compared to the ex ante tax.

25Even if the stochastic tax policy were designed to yield an equilibrium average U.S. market share of $60 \%$, the ex post certain tax would still be dominated by the ex post stochastic tax. For instance, an $85 \%$ VIE target implemented through an ex post tax with a probability of .4 (not shown in Table 1), results in an average market share of $60 \%$ but generates a higher consumer surplus and welfare: 4.11 and 6.67 , respectively, compared to the ex post certain tax. 
How do the stochastic tax and ex post subsidy compare? While the consumer price of the U.S. good is roughly the same for both, the ex post subsidy produces a smaller price for the Japanese good. This is reflected in a higher consumer surplus of 5.05 for the ex post subsidy. On the other hand, Japanese profit plus tax revenue with the ex post stochastic tax is greater than profit less subsidy expenditure for the ex post subsidy. Using our measure of welfare, we find that the ex post subsidy is marginally superior to the ex post stochastic tax in this example. Note that with either the ex post subsidy or the ex post stochastic tax the actual U.S. market share realized may fall short of the mandated minimum.

\section{Conclusion:}

The current U.S. preoccupation with negotiating minimum market share targets with the Japanese government has raised many questions regarding the economic consequences of these targets. However, recent work to analyze these questions has paid little attention to the implementation aspect, even though it is well understood that enforcement is critical to the success of any results-oriented policy. This paper explicitly considers tax and subsidy instruments to implement minimum market share agreements and demonstrates that their effects depend critically on the sequence of moves between government and firms. In particular, when the home government can move only after firms have made their strategic choices (ex post policy), both taxes and subsidies create powerful incentives for firms to raise prices - incentive effects that are absent in the traditional ex ante timing framework.

Under subsidy policy with monopoly power on the U.S. side, the incentives are for the U.S. firm to raise price and trigger the subsidies. If monopoly power is on the Japanese side, the incentives are for the Japanese firm to try and ensure that the subsidies are not triggered since such an occurrence lowers sales without a compensatory high price. Thus, 
it raises price to prevent subsidies (and reduce their amount) to the U.S. firms. In either case, under the ex post timing structure, subsidies create incentives to raise prices. If the minimum import requirement is implemented by a tax on the Japanese good and market power is on the U.S. side, then the incentives are for the U.S. firm to raise its price, triggering taxes on the Japanese good, which in turn enhances demand for the U.S. firm's product and increases its profit. If power is on the Japanese side, then the incentive is always to prevent taxes from being invoked by charging higher prices. Here, too, a timing structure with government as second mover produces incentives that result in higher prices. Thus, both tax and subsidy schemes, in the presence of market power, are anticompetitive in their effects. These incentive effects, while well documented for quotas/VERs, are not found in the literature on tax/subsidy policy.

These anticompetitive effects are mitigated to some extent when the government's enforcement ability is less than perfect. Some degree of imprecision in implementing the VIE target reduces the firms' power to strategically exploit the target and yields less anticompetitive outcomes - a fact which may account, in part, for the Japanese government's steadfast opposition to precise numerical targets. Further, imperfect enforcement gives rise to situations where the actual market share realized by the foreign firm falls short of the VIE target - a phenomenon frequently observed in the case of the semiconductor VIE. Hence, our framework captures, albeit loosely, some aspects of MITI's handling of the semiconductor VIE.

Given the anticompetitive nature of the specific tax and subsidy instruments considered so far, the natural question that arises is: 'are there situations in which an import target can be implemented without raising prices?' This issue is examined in depth in Krishna, Roy and Thursby (1996) where we show that such pro-competitive policies are indeed possible. 


\section{References:}

1. Bjorksten, Neil, 1994, "Voluntary Import Expansions and Voluntary Export Restraints in an Oligopoly Model with Capacity Constraints", Canadian Journal of Economics 27, 446-57.

2. Brainard, S. Lael and David Martimort, 1992, "Strategic Trade Policy with Incompletely Informed Policymakers", Working Paper No. 4069, National Bureau of Economic Research, Inc.

3. Brander, J.A. and B.J. Spencer, 1985, "Export Subsidies and International Market Share Rivalry", Journal of International Economics 18, 83-100.

4. Carmichael, Calum M., 1987, "The Control of Export Credit Subsidies and its Welfare Consequences", Journal of International Economics 23, 1-19.

5. Cronshaw, Mark B. and James R. Markusen, 1995, "The Theory and Consequences of Results-Oriented Trade Policy", in: Alan V. Deardorff, Jim Levinsohn and Robert M. Stern, eds., New Directions in Trade Theory (The University of Michigan Press, Ann Arbor), 295326.

6. Dinopoulos, Elias and Mordechai Kreinin, 1990, "An Analysis of Import Expansion Policies", Economic Inquiry 28, 99-108.

7. Eaton, J. and G.M. Grossman, 1986, "Optimal Trade and Industrial Policy under Oligopoly", The Quarterly Journal of Economics 101, 383-406.

8. Ethier, Wilfred J. and Henrik Horn, (1993), "Results-Oriented Trade Policy", Discussion Paper No. 304, The Institute of Social and Economic Research, Osaka University.

9. Goldberg, Pinelopi K. and Michael M. Knetter, (1995), "Causes and Consequences of the Export Enhancement Program for Wheat", Working Paper 5359, National Bureau of Economic Research, Inc.

10. Greaney, Theresa, 1995, "Import Now! An Analysis of Market-Share Voluntary 
Import Expansions (VIEs)", (forthcoming) Journal of International Economics.

11. Gruenspecht, Howard K., 1988, "Export Subsidies for Differentiated Products", Journal of International Economics 24, 331-344.

12. Helpman, Elhanan and Paul R. Krugman, 1989, Trade Policy and Market Structure, The MIT Press, Cambridge, Massachusetts.

13. Irwin, Douglas A., 1994, Managed Trade: The Case Against Import Targets, The AEI Press, Washington, D.C.

14. Irwin, Douglas A., 1996, "Trade Politics and the Semiconductor Industry", in: Anne O. Krueger, ed., The Political Economy of American Trade Policy (The University of Chicago Press, Chicago), 11-66.

15. Kowalczyk, Carsten, 1994, "Monopoly and Trade Policy", Journal of International Economics 36, 177-186.

16. Krishna, Kala, 1989, "Trade Restrictions As Facilitating Practices", Journal of International Economics 26, 251-270.

17. -_.-, 1990, "The Case of the Vanishing Revenues: Auction Quotas with Monopoly", American Economic Review 80, 828-836.

18. Krishna, Kala, Suddhasatwa Roy and Marie Thursby, 1996, "Pro-competitive Market Access", mimeo.

19. Nakamura, Hiroshi, 1995, "Does a Minimum Share Target Really Increase Competition in an Importing Country?", in: Ph. D. dissertation, Stanford University.

20. Singh, Nirvikar and Xavier Vives, 1984, "Price and quantity competition in a differentiated duopoly", Rand Journal of Economics 15, 546-554.

21. Tyson, Laura D'Andrea, 1992, Who's Bashing Whom: Trade Conflict in High Technology Industries, Washington, D.C.: Institute for International Economics. 


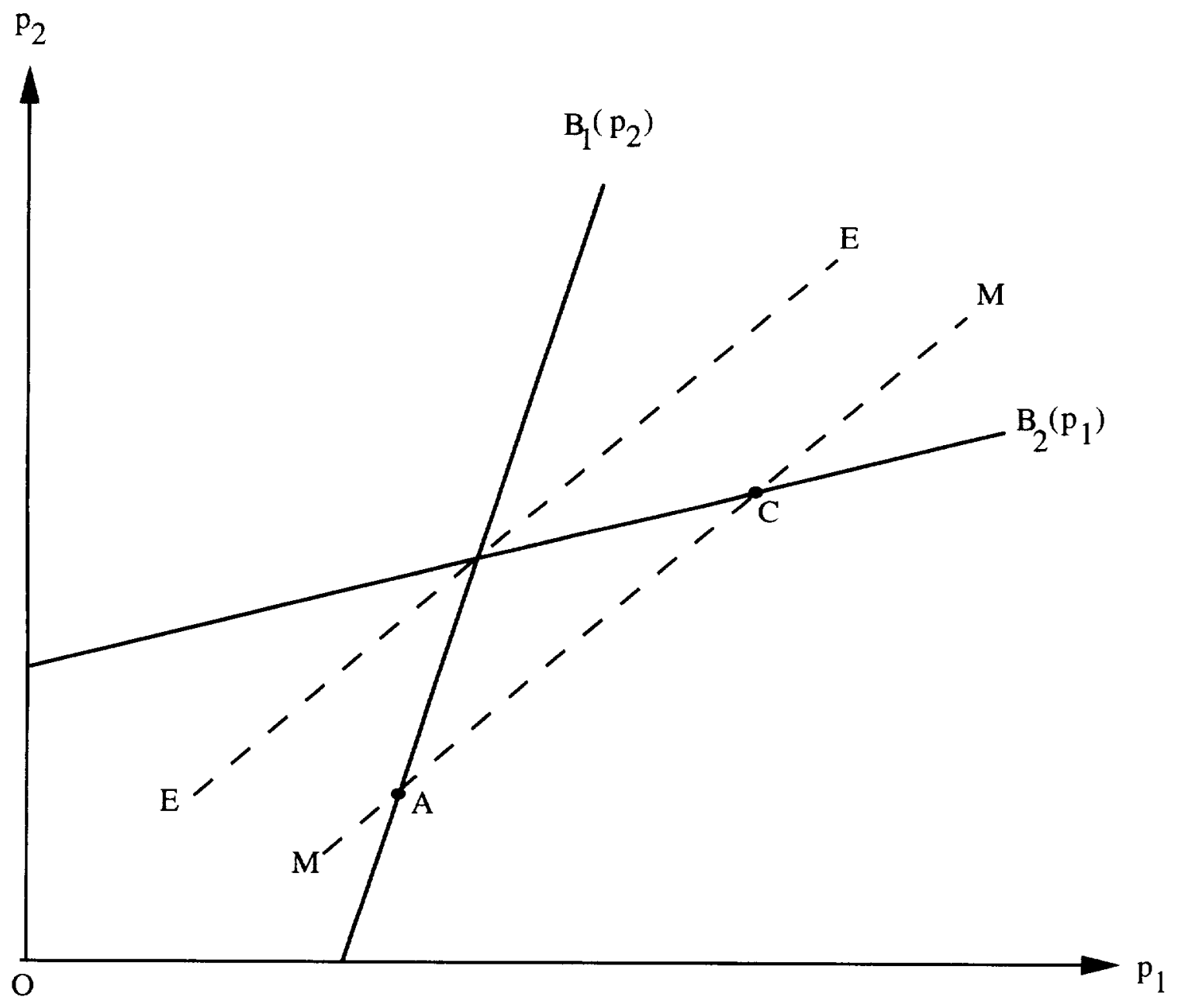

Figure 1 


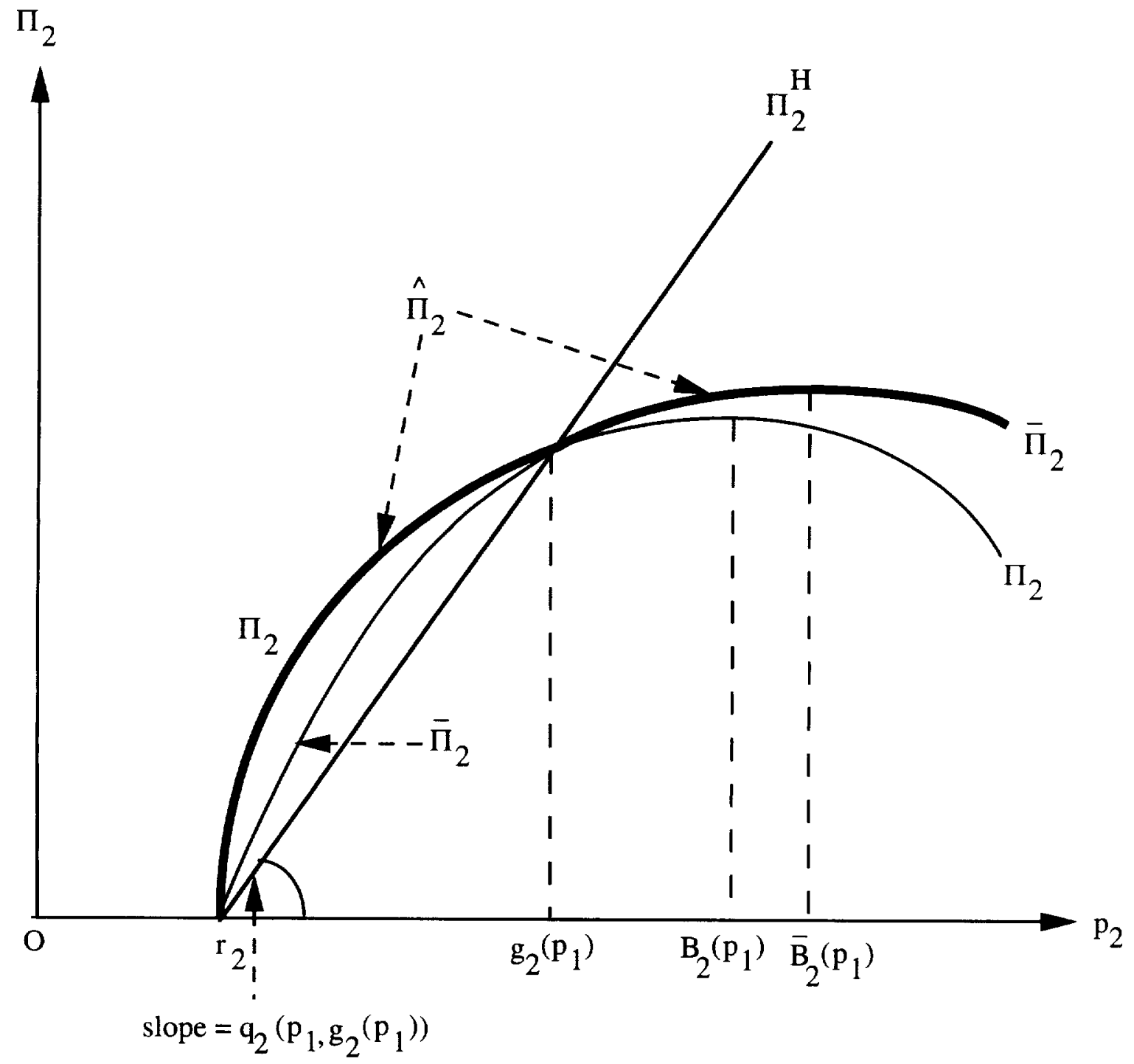

Figure 2 


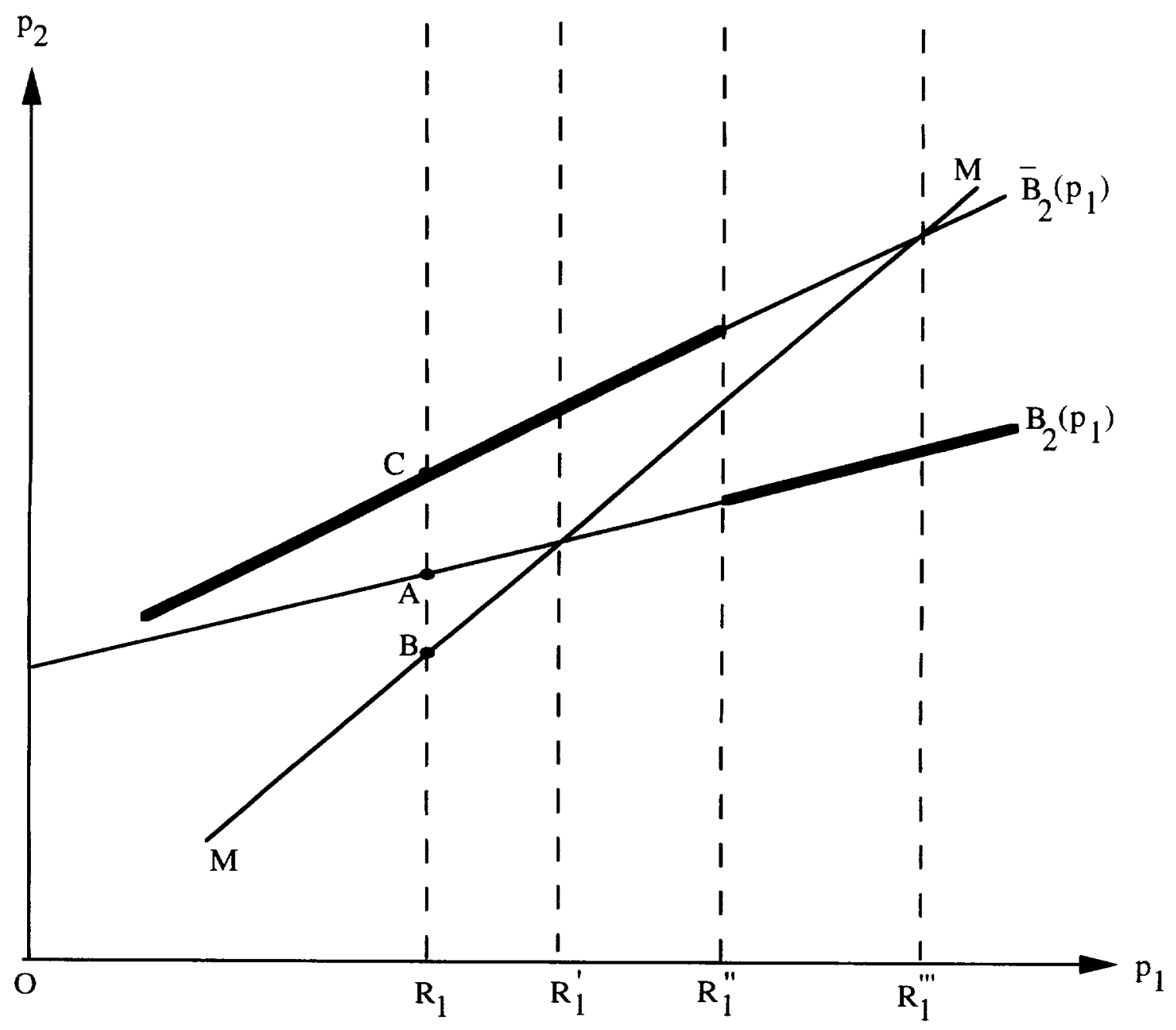

Figure 3 


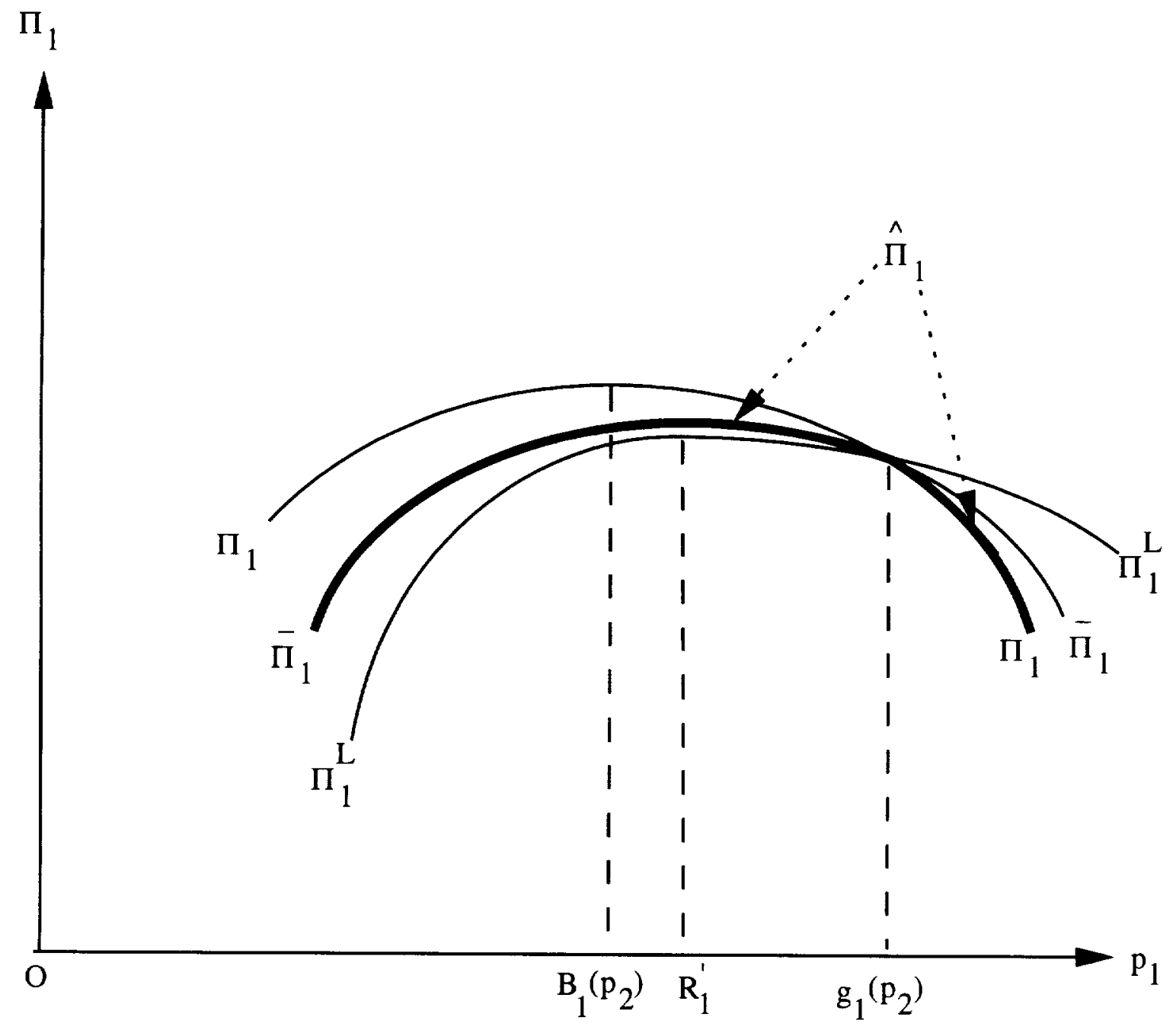

Figure 4 


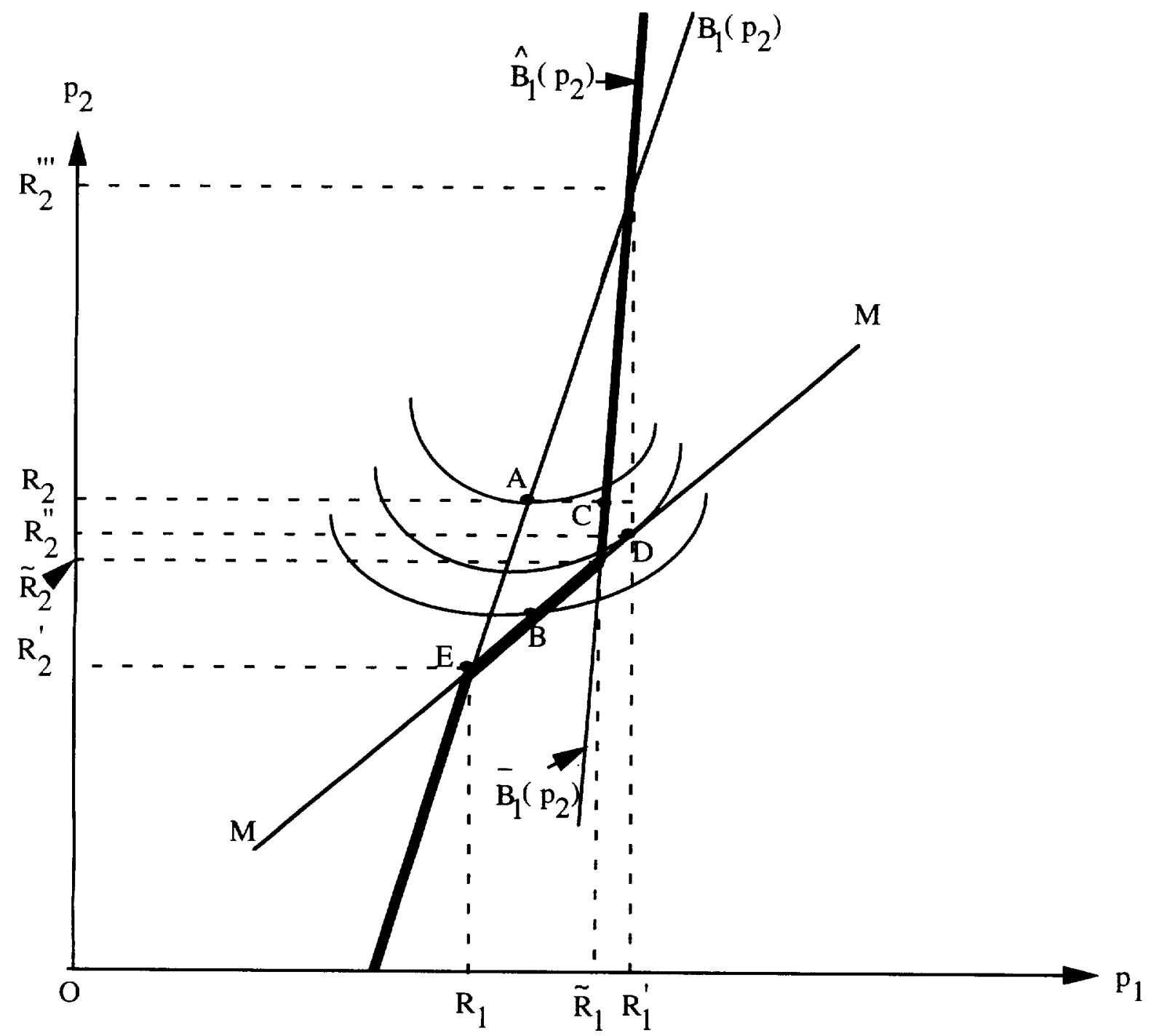

Figure 5 


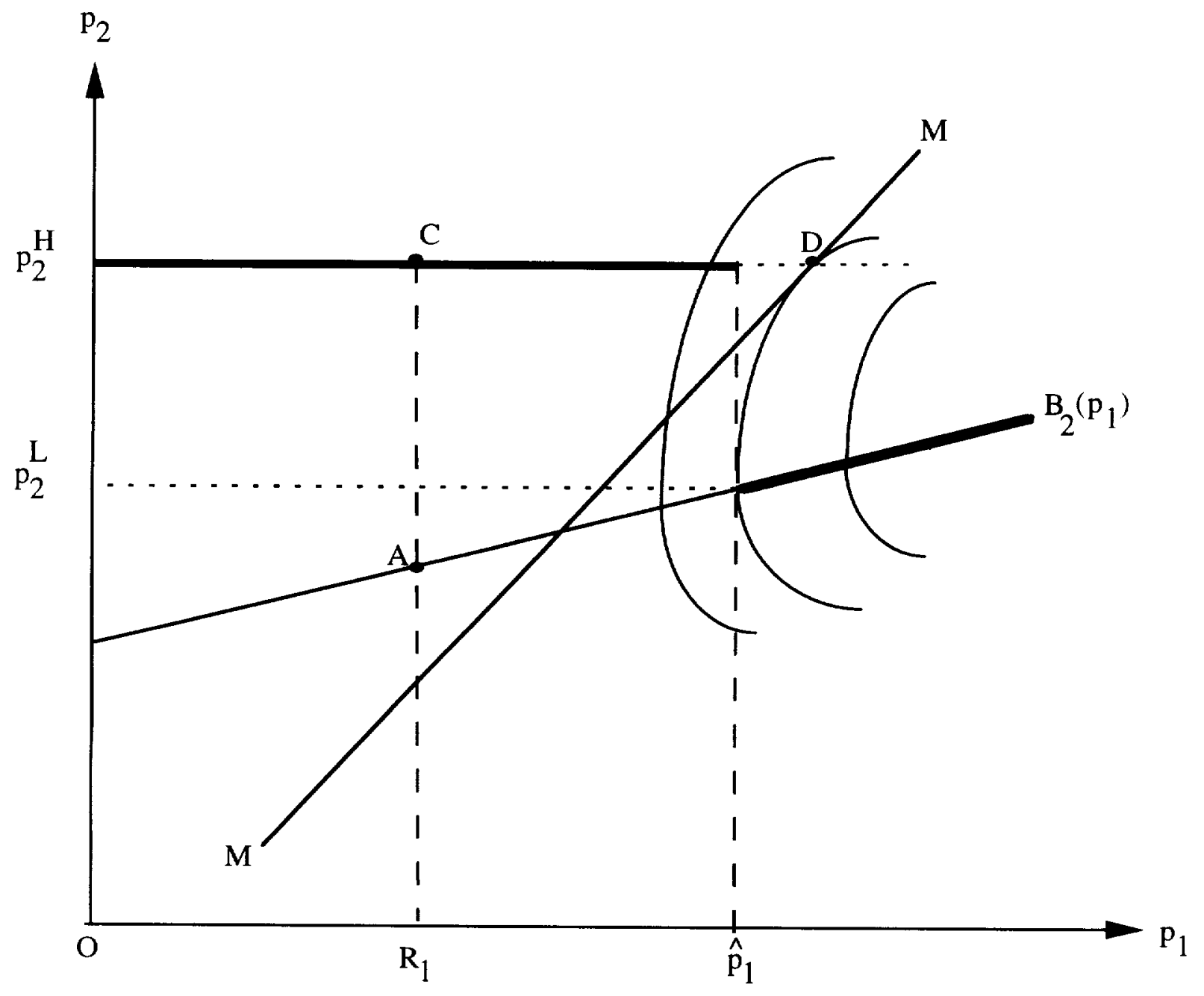

Figure 6 


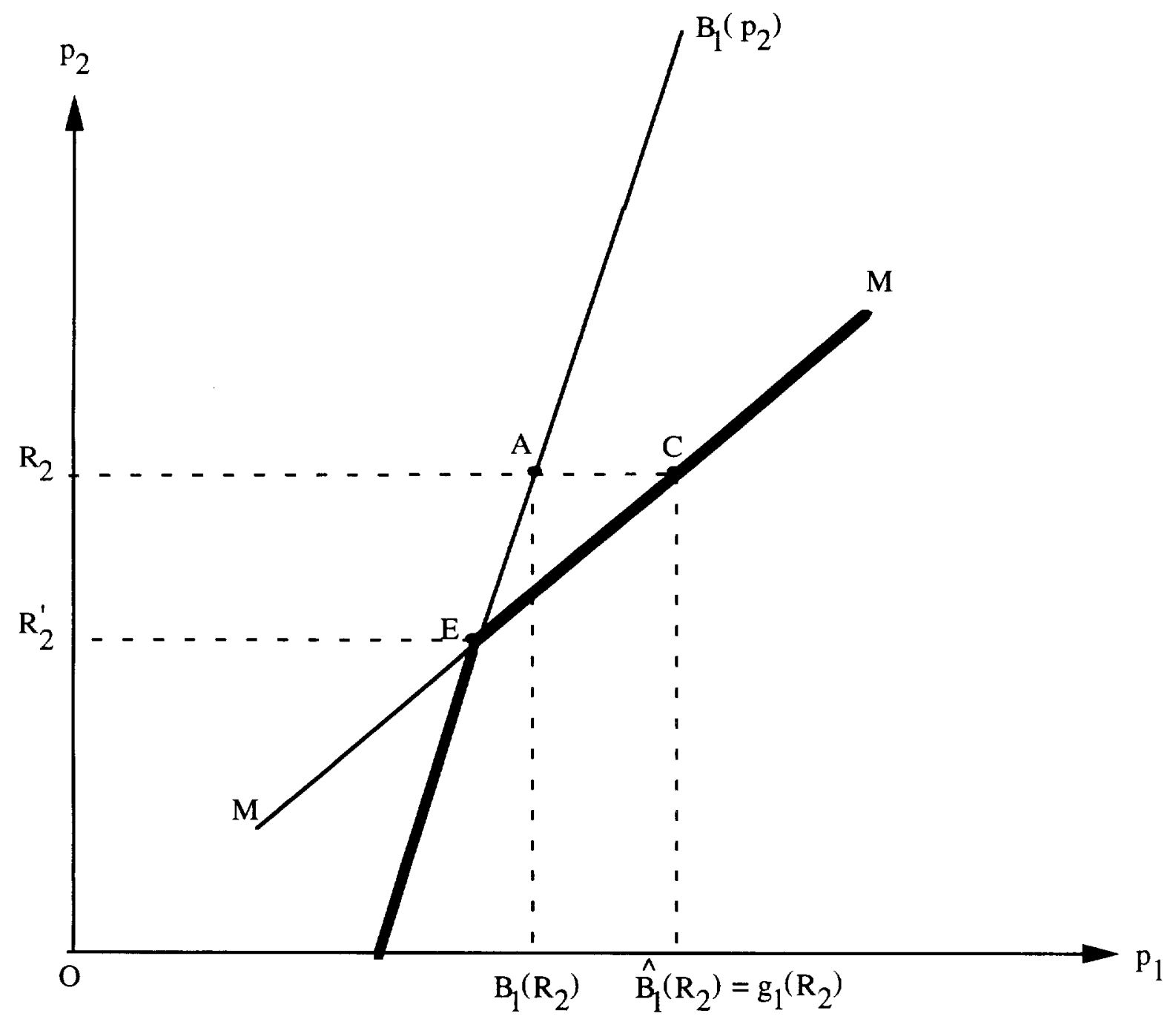

Figure 7 


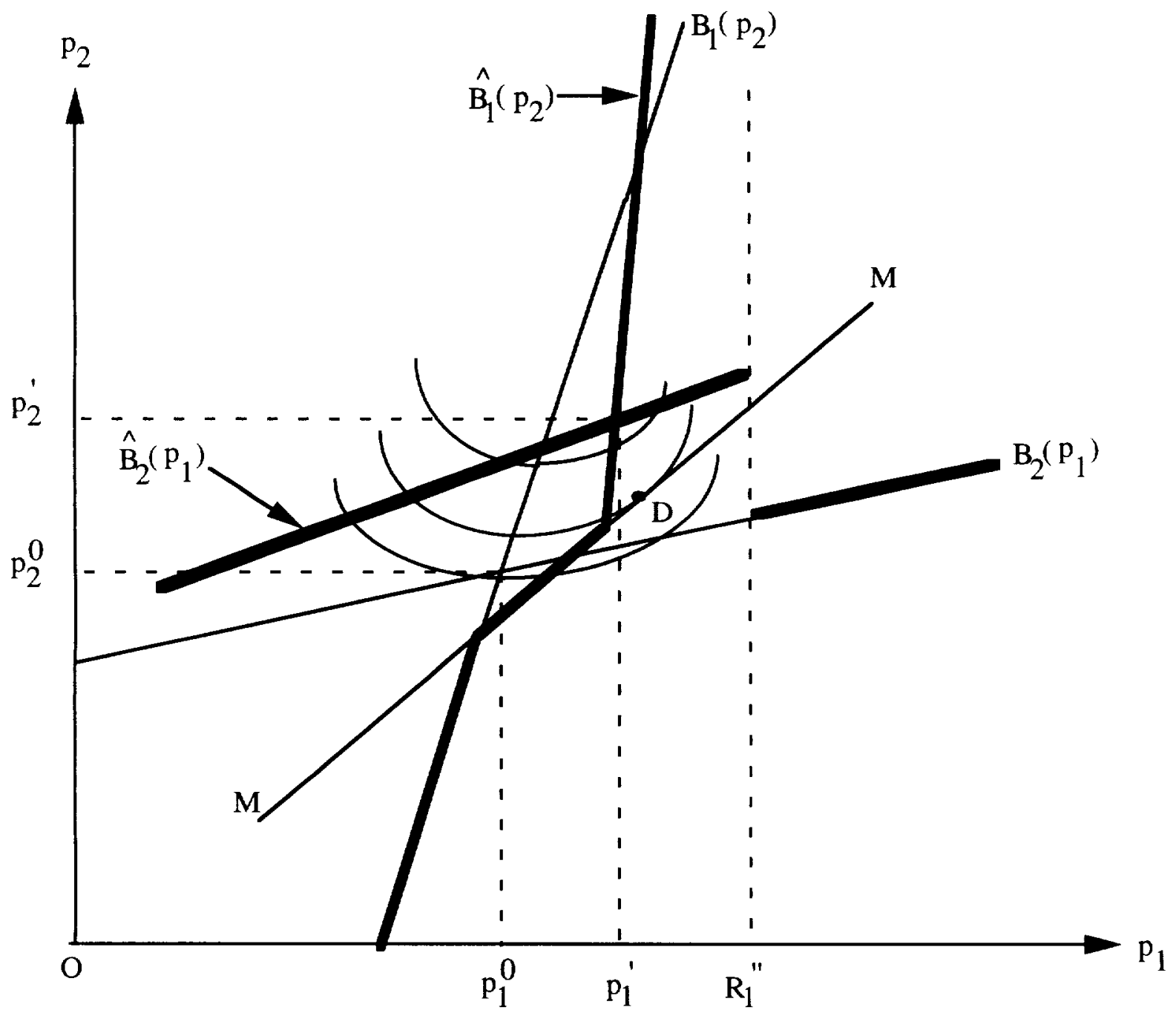

Figure 8 


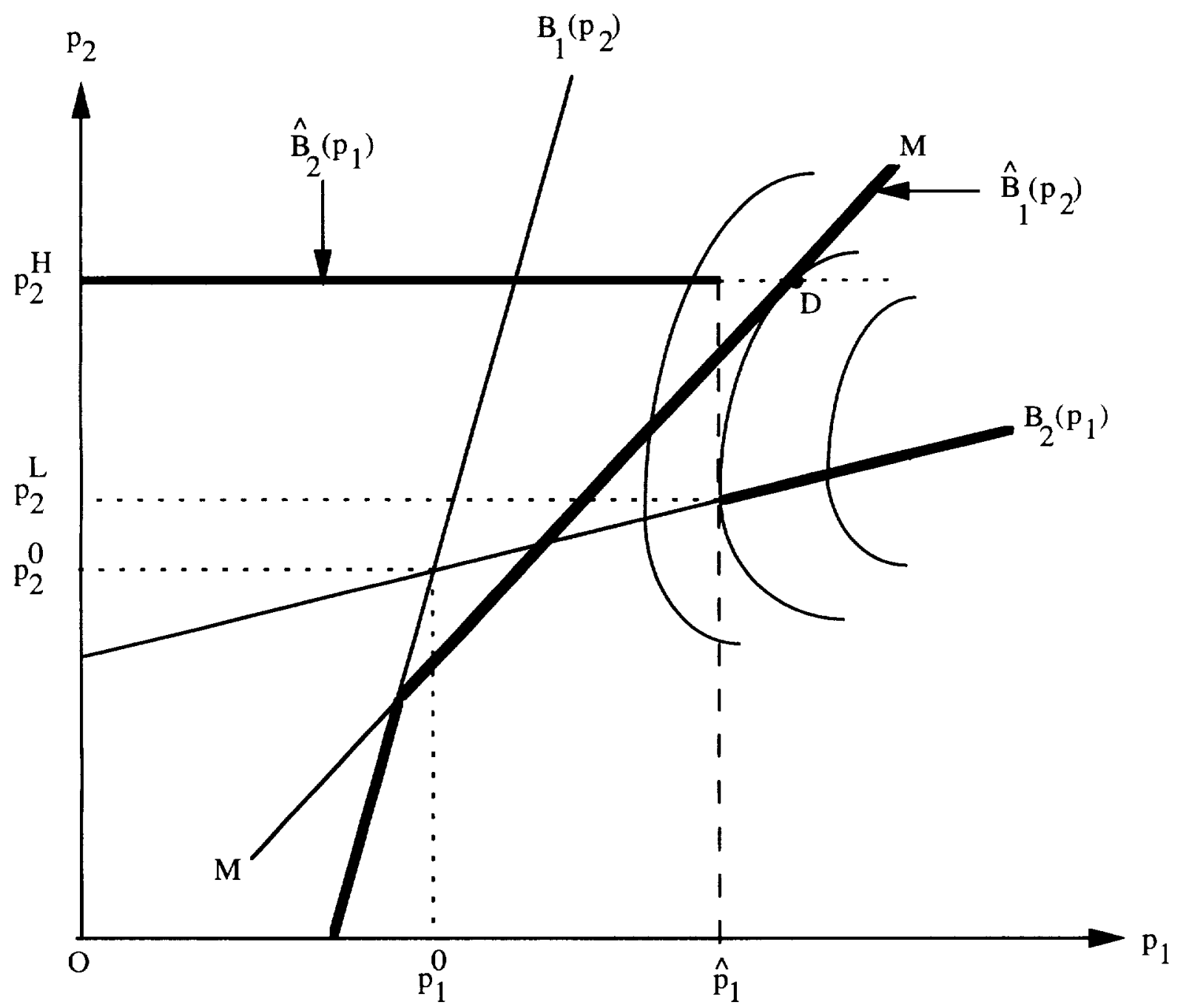

Figure 9 
Table 1.* Firm and consumer prices, quantities, profits, subsidy expenditures, tax revenues, consumer surplus and welfare for const. probability .2 and VIE target 0.6

\begin{tabular}{|l|l|l|l|l|l|l|}
\hline & $\begin{array}{l}\text { No VIE } \\
\text { target }\end{array}$ & $\begin{array}{l}\text { Ex ante } \\
\text { Subsidy }\end{array}$ & $\begin{array}{l}\text { Ex ante } \\
\text { Tax }\end{array}$ & $\begin{array}{l}\text { Ex post } \\
\text { Subsidy }\end{array}$ & $\begin{array}{l}\text { Ex post } \\
\text { Certain Tax }\end{array}$ & $\begin{array}{l}\text { Ex post } \\
\text { Stoch. Tax }\end{array}$ \\
\hline Jap. firm price & 2.27 & 2.10 & 1.80 & 2.37 & 3.00 & 2.39 \\
\hline U.S. firm price & 2.07 & 2.65 & 2.20 & 2.28 & 2.54 & 2.17 \\
\hline Jap. cons. price & 2.27 & 2.10 & 2.80 & 2.37 & 3.14 & 2.47 \\
\hline U.S. cons. price & 2.07 & 1.40 & 2.20 & 2.16 & 2.54 & 2.17 \\
\hline Jap. quantity & 2.53 & 2.20 & 1.60 & 2.43 & 1.25 & 2.23 \\
\hline U.S. quantity & 2.13 & 3.30 & 2.40 & 2.04 & 2.07 & 2.13 \\
\hline Jap. profit & 3.21 & 2.42 & 1.28 & 3.32 & 2.50 & 3.11 \\
\hline U.S. profit & 2.28 & 5.45 & 2.88 & 2.61 & 3.13 & 2.49 \\
\hline Subsidy expen. & NA & 4.13 & NA & .34 & NA & NA \\
\hline Tax revenue & NA & NA & 1.6 & NA & .18 & .12 \\
\hline Jap. cons. surplus & 5.44 & 7.66 & 4.05 & 5.05 & 2.83 & 4.79 \\
\hline Jap. welfare & 8.66 & 5.96 & 6.93 & 8.03 & 5.51 & 8.02 \\
\hline
\end{tabular}

*Numbers have been rounded off to two decimal places. 